\title{
A Review of Somatic Embryogenesis in Cucurbitaceae
}

\author{
Li Zhang, Jia Lai, Yi Tang, Qian Luo, Yongpeng Zhu and Huanxiu Li \\ College of Horticulture, Sichuan Agricultural University, Ya'an 625014, Sichuan, China
}

Received: September 29, 2012 / Published: January 20, 2013.

\begin{abstract}
Somatic embryo is widely used in genetic engineering and cell engineering. This paper reviewed the recent research results of somatic embryogenesis in Cucurbitaceae plants. Somatic embryogenesis is controlled by many factors such as genotype, explant type, seedling age, basal culture medium, carbohydrate, nitrogen, growth regulators, additives and illumination et al.. Abnormality, desynchrony and browning are the main problem existing in Cucurbitaceae somatic embryogenesis. Then some ideas on how to obtain high quality somatic embryo are given. At last, we forecast the application of somatic embryo in breeding of Cucurbitaceae plants.
\end{abstract}

Key words: Somatic embryogenesis, Cucurbitaceae, growth regulators, abnormality.

\section{Introduction}

Plant embryogenesis is a series of successive process after fertilization, which includes the regular transmutations from zygocyte to mature embryo. Zygotic embryo is the embryo produced in this way. Plant cell, tissue and organ cultured in vitro could produce something similar with embryo in structure and generate process, so it is called embryoid or somatic embryo [1]. Somatic embryo could be mass-produced in a short time, the reproduction rate of somatic embryo is high, and it is easy to develop into plantlet. Somatic embryo provides perfect material for artificial seed, haploid breeding and asexual propagation. Moreover, somatic embryo has little somaclonal variation while has high capability to accept exogenous DNA, so it is used as receptor system of genetic modification in many plant species [2].

The Cucurbitaceae is a moderately large family consisting of about 130 genera and 900 species [3]. Its main cultivated species are of significant value as fruits or vegetables in the tropics, subtropics and milder portions of the temperate zones of both

Corresponding author: Huanxiu Li, professor, research field: application of biotechnology in horticulture plant. E-mail: hxli62@163.com. hemispheres [4]. Conventional breeding of Cucurbitaceae takes long time and the hereditary trait is unstable. Regeneration frequency is low and propagation period is long via organogenesis in Cucurbitaceae, furthermore, somaclonal variation is serious, thus it is difficult to meet the demand of research and agricultural production. Plant regeneration via somatic embryogenesis has important theoretical significance and using value to the rapid propagation, germplasm conservation and breeding of excellent variety in Cucurbitaceae [5]. This paper reviewed the factors affecting somatic embryogenesis in Cucurbitaceae, described the problems existing, and forecasted the development in the future.

\section{Plant Somatic Embryogenesis}

Somatic embryogenesis has two different paths: one is inducing somatic embryo from plant tissue such as nucellus and synergid directly; the other path is inducing somatic embryo from embryonic callus tissue which was induced from plant tissue [6]. Somatic embryos were formed from the inside or the surface of callus, the surface of explant, adventitious root and meristem of explant vascular via indirect path in most of plant species. The process of somatic embryogenesis mainly includes inducing of 
embryonic callus tissue, propagation of embryonic callus, maturation of somatic embryo, germination of somatic embryo and developing into plantlet [7].

Since Reinert [8] and Steward et al. [9] described somatic embryogenesis in carrot (Daucus carota L.) for the first time, much progress was made in the research of somatic embryo. In Cucurbitaceae, Malepszy et al. [10] reported somatic embryogenesis of cucumber (Cucumis sativus L.) for the first time, $\mathrm{Yu}$ and $\mathrm{Zhu}$ [11] obtained somatic embryo from mature embryos of cucumber and developed into plantlet, Yin et al. [12] regenerated plantlets from somatic embryo of Cucumis melo L.. Somatic embryo is widely used in breeding over recent years, especially as the receptor system of genetic modification.

\section{Factors Controlling Somatic Embryogenesis}

Factors controlling somatic embryogenesis could be divided into endogenic factors and exogenic factors. Endogenic factors include different species of plant and genotype of variety, while it is also related to the maturation degree of plant and difference of explant. Exogenic factors include media composition and physical factors $[13,14]$.

\subsection{Genotype}

Most plants have potential to induce somatic embryo, but the complexity of inducing is different; and the frequency of somatic embryogenesis is widely different as the difference of genotype in the same species [15]. Nadolska-Orczyk and Malepszy [16] suggested a genetic determinism in the ability to regenerate somatic embryo derived plants from cucumber (Cucumis sativus L.) leaf explants. Carol et al. [17] studied the somatic embryogenesis of six squash cultivars, all cotyledons produced somatic embryos after 11 to 17 weeks on induction medium. However, the optimal culture time and the rate of plant regeneration were significantly different between the six cultivars. Significant differences of somatic embryogenesis were observed among different cultivars in melon [18] and watermelon [19]. The frequency of somatic embryogenesis could be inherited [20], just like what observed by Toshiro [18].

\subsection{Explant}

Type of explant is an extremely important factor in somatic embryogenesis. Somatic embryogenesis is reported using diverse types of explants in Curcurbitaceae, for example, petiole [21], root [22], protoplast [23-24], unfertilized ovaries [25], leaf disc [26], hypocotyl [27], cotyledon [28], hairy roots [29], unfertilized ovules [30] and nucellus [31]. However, seedling material, such as cotyledon and hypocotyl tissues, is especially successful [32], because of the vigorous metabolism and low differentiation level in these tissues [33].

\subsection{Seedling Age}

Physiological age of explant is a key factor to determine whether the somatic embryo could be induced. Leaves of cucumber from 20-d-old in vitro raised seedlings produced friable and shiny pale green embryogenic callus [34]. Zeng et al. [35] put cotyledons from 4-8-d-old seedlings of melon on induction medium, somatic embryo is observed in all of the explants, but the most somatic embryos are obtained from 5-d-old seedlings. Zhang [19] discovered that cotyledons of 4-15-d-old watermelon seedlings could induce somatic embryo, but the frequency of induction varies greatly because of the difference in seedling age. Cotyledons of 5-6-d-old seedlings induce the most somatic embryo, only a few somatic embryos are obtained from cotyledons of over 10-d-old seedlings. Anyway, seedling age affects frequency of somatic embryogenesis significantly. However, growth rate of seedling in different varieties is influenced by genotype and physical factors, so it is more effective to use the color of cotyledon as a standard of seedling age. 


\subsection{Basal Culture Medium}

Somatic embryogenesis is also affected by basal culture medium, medium applied in somatic embryogenesis include MS, WPM, SH and B5 etc.. Jelaska [36] noted that somatic embryogenesis did not occur when squash (Cucurbita pepo L.) was cultured on $\mathrm{H}$ mineral medium. Zhang [19] cultured cotyledon of watermelon on MS, B5 and N6 medium, the most somatic embryos were obtained by MS medium. MS is also the best medium in the research of melon [37]. In a word, MS medium is the first choice of somatic embryogenesis in Cucurbitaceae.

\subsection{Carbohydrate}

Carbohydrate is indispensable in the induction of somatic embryo, because it could be used as carbon source, energy source and osmoregulatory agent. Oridate and Yasawa [38] observed that sucrose, glucose, fructose and galactose led to a high frequency of somatic embryos. However, fructose and galactose were the best for embryo development. Xu and Jia [39] reported that somatic embryo of melon is directly occurred on medium containing lactose or maltose, while somatic embryo is obtained on medium containing sucrose or glucose via indirect pathway. Somatic embryogenesis of cucumber is severely inhibited on medium containing maltose, lactose or melibiose [40], sucrose is more effective in somatic embryo production than other sugars [34]. Mannitol is useful for somatic embryogenesis of cucumber as osmoregulatory agent, while sorbierite inhibit the induction of somatic embryo [41].

It is proved that higher permeability could promote the frequency of somatic embryogenesis [42]. Chee and Tricoli [43] showed that 5\% sucrose was better for somatic embryogenesis from cucumber cell suspensions. The most somatic embryos are obtained from melon cotyledon on medium containing $2 \%$ sucrose, frequency of somatic embryogenesis reduced as the increase of sucrose, only a few somatic embryos are obtained on medium containing $12 \%$ sucrose [39].
Furthermore, plant regeneration from somatic embryo could be inhibited by physiological dehydration as a result of high permeability.

\subsection{Nitrogen}

Somatic embryogenesis requires plenty of nitrogen and it is affected by the state and concentration of nitrogen. Nitrogen of in vitro culture could be provided by nitrate, ammonium salt and amino acid [44]. Somatic embryogenesis in pumpkin can be induced on hormone-free medium containing $1 \mathrm{mM}$ ammonium $\left(\mathrm{NH}_{4}{ }^{+}\right)$as the sole source of nitrogen. Growth of $\mathrm{NH}_{4}{ }^{+}$ induced embryogenic tissue was slow and caused considerable acidification of the culture medium. Small spherical cells with dense cytoplasma formed proembryogenic cell clusters that could not develop into late stage embryos. Buffering of $\mathrm{NH}_{4}{ }^{+}$medium with $25 \mathrm{mM}$ 2-(N-morpholino)-ethane-sulfonic acid enhanced tissue proliferation, but no further differentiation was observed. Later, stage embryos developed only after resupply of nitrogen in form of nitrate or L-glutamine [45].

\subsection{Growth Regulators}

For the most part, explants cultured on basal medium can only keep the basic physiological activity, application of growth regulators ensure the accomplishment of diverse activities such as induction, multiplication, differentiation and regeneration [46]. Explants of melon on hormone-free medium can not produce callus or adventitious bud, and perish at last [37]. Many researches indicate that somatic embryogenesis is affected by the kind, concentration and combination of plant regulators [47].

Auxin has decisive effect in the early period of somatic embryogenesis [48], its proper application is important to the induction [49]. Auxin is necessary for somatic embryogenesis in many plants $[50,51]$, while callus induction on auxin containing media and embryogenesis on auxin free medium is being used as standard method [52, 53]. 2,4-dichlorophenoxyacetic 
acid (2,4-D) is often used in somatic embryogenesis. Juretić and Jelaska [54] showed that MS medium containing IBA and 2,4-D could induce embryogenic callus from hypocotyl explants of pumpkin; with summer squash, a high concentration of 2,4-D alone appears to be effective in inducing embryoid formation. However, Jelaska et al. [55, 56] observed different morphogenetic responses in squash tissue. Media with NAA or IBA produced embryos that were able to undergo complete development whereas most embryos were restricted to the globular stage on media with 2,4-D. Furthermore, Noël et al. [57] observed that squash embryo abnormalities were related to 2,4-D concentration in induction medium. These researches indicate that the application of 2,4-D should have a regular fluctuation, induce embryogenic callus in a higher concentration 2,4-D at first, then produce somatic embryo of early state in low concentration 2,4-D, at last remove 2,4-D once somatic embryo developed into globular embryo [46]. IAA is more effective than 2,4-D in induction of watermelon embryogenic callus, 2,4-D or combination of 2,4-D and 6-BA mainly induce non-embryonic callus, while combination of IAA and 6-BA induce more embryonic callus and somatic embryo [58]. Jelaska [36] reported the important value of IBA and NAA in somatic embryogenesis of pumpkin. Urbanek et al. [59] reported the callus proliferation of Styrian pumpkin was more efficient on medium with high concentrations of NAA and BA. In contrast, the embryogenic response was higher on medium with lower concentrations of NAA and BA. The germination rate was the highest when embryos in globular stage were cultured on medium with IAA.

Somatic embryogenesis could not occur with a single auxin in most plant species, combination of different plant regulators is important [60].

Cytokinin has been proved useful in somatic embryogenesis by plenty of researches. 6-BA is the most frequently applied plant regulator in cytokinin, as it could enhance the inducing frequency and quantity of somatic embryo. However, vitrification could be observed in explant with high concentration 6-BA, so 6-BA should be removed once the formation of embryogenic callus [61]. Many plants those difficult to regenerate could obtain somatic embryo and regenerate plantlet successfully with the use of TDZ, but the function of TDZ could be promoted or inhibited in different plant species even in different varieties of the same plant species [62], and it could be affected by the concentration and time of treatment [63]. Initial pretreatment of squash leaf explants with $186 \mu \mathrm{M}$ kinetin for $48 \mathrm{~h}$ significantly promoted the formation of somatic embryos which developed further to the torpedo-shape stage and germinated. The regeneration rate achieved an increase over non-pretreated cultures of $143 \%$ [64]. Compton and Gray [65] cultured immature cotyledons of watermelon on medium containing 2,4-D and TDZ, somatic embryos are induced from surface of cotyledons and then develop into plantlets, while only adventive buds produced on medium containing 2,4-D and 6-BA. On the contrary, the colorless, friable and embryogenic callus become green, campact and non-embryogenic when TDZ is applied in somatic embryogenesis of alfalfa [66]. Paula [67] reported that maturation of squash somatic embryo is affected by NAA and KT.

ABA is often used in induction of embryogenic callus, as it has a powerful function in adjusting and controlling the occurrence and development of somatic embryo [68]. ABA could promote the differentiation of somatic cell and inhibit the formation of early-stage somatic embryo, it can be used to make somatic embryogenesis in synchronization $[69,70]$. ABA is also important to the maturation of somatic embryo, as it can accelerate the maturation of somatic embryo and prevent the happening of polyembryony and abnormality [71, 72].

In the ordinary way, endogenous gibberellin could meet the explants' demand of growing and development, so gibberellin is seldom used in somatic 
embryogenesis compared with other plant regulators, but it could promote cell's elongation growth and somatic embryo's germination [73]. Under some conditions, gibberellin could enhance the activity of auxin and cytokinin [46]. Combination of 6-BA, KT and $\mathrm{GA}_{3}$ induced plenty of watermelon somatic embryos by Shanshan et al. [74].

\subsection{Additives}

Additives often used in tissue culture include natural organic nutrients, active carbon and metal ion. Natural organic nutrients such as malt extract (ME), casein hydrolysate $(\mathrm{CH})$ and coconut milk $(\mathrm{CM})$ are rich in various kinds of amino acids, which could provide reduction state nitrogen that was metabolized more easily than inorganic nitrogen [75]. Active carbon (AC) in medium could absorb inhibitor that prevents the induction of somatic embryo and it could reduce browning rate effectively [76]. Metal ion could reduce the interference of ethylene to polyamine biosynthesis, and thus promote the induction of somatic embryo. The use of silver nitrate improved somatic embryogenesis in several plant species such as buffalo grass [77] and Coffea sp. [78, 79].

\subsection{Illumination}

The somatic embryogenesis of different plants demand different illumination, some need in light, some need in dark, and some are unlimited by illumination [80]. Weatherwax et al. [81] believed that photoperiod changes the levels of endogenous $\mathrm{ABA}$ by means of phytochrome and finally influence somatic embryogenesis. Zheng et al. [27] proved that production of watermelon callus need cultured in dark, seven days and then transfer to light, thus favored the rapid propagation of white callus and promote them to develop into yellow callus, yellow callus is excellent material for inducing somatic embryo [82, 83]. Han et al. [84] discovered that melon cotyledon explants cultured one week in darkness, followed by another week photoperiod before transferring to embryos development medium, produced more mature embryos.

\section{Desynchrony and Abnormality}

The development process of somatic embryo was similar with zygotic embryo including globular embryo, heart-shape embryo, torpedo-shape embryo and cotyledon embryo. Desynchrony and abnormality are common in plant somatic embryogenesis, production of somatic embryo from embryogenic callus is not in the same phase, somatic embryo in different period could be observed in the same callus, thus it is difficult to establish synchronous somatic embryo regeneration system; formation of abnormal somatic embryo prevents the maturation and transformation of somatic embryo [85]. Somatic embryogenesis in Curcurbitaceae also exists desynchrony and abnormality, which include cotyledon absence, oversize cotyledon, cotyledon amalgamation, cotyledon abnormality, polyembryony amalgamation and advance germination of somatic embryo in each stage [86]. Somatic embryogenesis in cucumber is generally limited by low efficiency or the formation of abnormal embryos [34]. Suspension culture of embryonic callus tissue is an effective measure to enhance the frequency of somatic embryogenesis and make it in phase [75]. Normal development of somatic embryo could be improved by means of two-layer culture, higher concentration sucrose and adjunction of ABA or active carbon [11].

\section{Browning}

Browning is common in vitro culture present viewpoint believes that browning is caused by enzymatic catalysis. Browning is affected by plenty of factors such as plant species, genotype, explant type, physiological status of plant and medium composition. In common, browning is lighter in young plant than old plant in growing season contains more phenolic compound and tending to brown, so drawing materials should be done in early spring or autumn. Injured 
level of explant is also a factor leading to browning, in order to lighten browning, wound area should be decreased and wound should be smoothy when cutting explants. Reducing the concentration of inorganic salt, 6-BA and KT etc. in medium could lighten browning. Callus grows well and browning is light when adding active carbon in medium, but the reproduction rate is lower than medium without active carbon, which proves that active carbon adsorbed plant regulator and nutrient substance when absorbing harmful metabolin [37].

\section{Maturation and Regeneration}

Somatic embryo could mature and regenerate in basal medium after induction from medium containing plant regulator and nutrient substance in theory. Development and maturation of cucumber somatic embryos could be done on auxin free medium [26, 31]. However, maturation and regeneration of some plants need special condition. For example, in the research of cucumber by Vengadesan et al. [34], maturation of somatic embryos occurred on plant growth regulator-free MS semi-solid medium containing $175.2 \mathrm{mM}$ sucrose and $0.5 \mathrm{~g} / \mathrm{L}$ activated charcoal. Conversion of embryos into plants was achieved on half-strength MS semi-solid medium containing 87.6 $\mathrm{mM}$ sucrose and $1.4 \mu \mathrm{M}$ gibberellic acid in a $16 \mathrm{~h}$ photoperiod. $27 \%$ of embryos were converted into normal plants.

\section{Conclusions}

Particular attention has been paid to somatic embryogenesis in recent years because of its advantage in genetic engineering and cell engineering. Improve directly and innovate variety by introducing exogenous gene into the genome of somatic embryos and making it express effectively and inherit steadily in plant, which opening up a new channel for breeding research of Cucurbitaceae. In addition, research of somatic embryo lays a foundation for conserving of germ plasm resource, production of artificial seed and rapid propagation. It is extremely important in theoretical research and application, which show a bright prospect in the development of agriculture.

Obtaining high quality somatic embryo is a foundation of genetic engineering and cell engineering. Plant growth regulator has a decisive effect on the differentiation, development and morphogenesis of somatic embryo, but the research related to the connection of plant growth regulator and endogenous hormones is still lacking, it is necessary to further explore the regulate function of plant growth regulator to endogenous hormones. For revealing the substance of somatic embryogenesis, molecular mechanism of somatic embryogenesis should be deeply studied, especially gene differential expression and control mechanism in cell differentiation of culture in vitro. Somatic embryogenesis of Cucurbitaceae has been studied widely and gained abundant results, however, a lot of flaws are still exist. For instance, somatic embryogenesis and plant regeneration of cucumber, melon and pumpkin has been studied deeply, but other species was seldom researched, abnormality, desynchrony and browning in somatic embryogenesis has not been controlled effectively. All these problems require further research to solve.

\section{References}

[1] D. Wang, Plant Tissue Culture, China Agriculture Press, Beijing, China, 2004.

[2] X.F. Yan, Transgenic Plants, Science Press, Beijing, China, 2003.

[3] C. Jeffrey, A review of the Cucurbitaceae, Bot. J. Linn. Soc. 81 (1980) 233-247.

[4] S. Jelaska, Cucurbits, in: Biotechnology in Agriculture and Forestry 2. Crops I, 1986, pp. 371-386.

[5] L.Y. Song, Z. Tan, F. Gao, S.Y. Deng, Advances in vitro culture of Cucurbitaceae in China, Chinese Bulletin of Botany 21 (2004) 360-366.

[6] Q.C. Liu, G.L. Wu, Plant Cell Tissue Culture, China Agricultural University Press, Beijing, China, 2010.

[7] X.L. Jin, P. He, Study and application on somatic embeyogenesis in arbor tree, Forest Research 16 (2003) 343-350.

[8] J. Reinert, Morphogenese und ihre Kontrolle an Gewebekulturen aus Carotten, Naturwissenschaft 45 
(1958) 344-345.

[9] F.C. Steward, M.O. Mapes, J. Smith, Growth and organized development of cultured cells, I. growth and division of freely suspended cells, Am. J. Bot. 45 (1958) 693-703.

[10] S. Malepszy, K. Niemirowicz-Szczytt, J. Wiszniewska, Cucumber (Cucumis sativus L.) somatic embryogenesis in vitro, Acta Biol 10 (1983) 218-220.

[11] Y.J. Yu, Q.J. Zhu, Embryoid induction and plantlet regeneration in mature embryos of cucumber in vitro, Plant Physiology Communications 28 (1992) 37-39.

[12] J. Yin, M.Y. Xu, X.P. Jia, R. Kan, L.G. Li, Somatic embryogenesis and plant regeneration of Cucumis melo $\mathrm{L}$. cv. Hetao, Acta Horticulturae Sinica 27 (2000) 455-457.

[13] M. Guis, J.P. Roustan, C. Dogimont, M. Pitrat, J.C. Pech, Melon biotechnology, Biotechnol. Gen. Eng. Rev. 15 (1998) 289-311.

[14] Y.L. Guan, Q. Pan, C. Ding, Some factors affecting plant somatic embryogenesis, Journal of Hainan Radio \& TV University 35 (2009) 114-116, 124.

[15] M. Galperin, A. Zelcer, D. Kenigsbuch, High competence for adventitious regeneration in the BU-21/3 melon genotype is controlled by a single dominant locus, Hort Science 38 (2003) 1167-1168.

[16] A. Nadolska-Orczyk, S. Malepszy, In vitro culture of Cucumis sativus L. 7. genes controlling plant regeneration, Theor. Appl. Genet. 78 (1989) 836-840.

[17] C. Gonsalves, B. Xue, D. Gonsalves, Somatic embryogenesis and regeneration from cotyledon explants of six squash cultivars, Hort Science 30 (1995) 1295-1297.

[18] T. Oridate, H. Atsumi, S. Ito, H. Araki, Genetic difference in somatic embryogenesis from seeds in melon (Cucumis melo L.), Plant Cell, Tissue and Organ Culture 29 (1992) 27-30.

[19] H.T. Zhang, Somatic Embryogenesis of Citrullus lanatus and Cytological Observations, Henan Agricultural University, Zhengzhou, China, 2004.

[20] S. Yuan, Y.J. Jia, H.H. Lin, Several physiological factors inducing somatic embryogenesis of plant, Plant Physiology Communications 39 (2003) 508-512.

[21] Z.K. Punja, N. Abbas, G.G. Sarmento, F.A. Tang, Regeneration of Cucumis sativus var. sativum and $C$. sativus var. hardwickii, C. melo and C. metuliferus from explants through somatic embryogenesis and organogenesis, Plant Cell Tiss. Org. Cult. 21 (1990) 93-102.

[22] A.J. Trulson, E.A. Shahin, In vitro plant regeneration in the genus Cucumis, Plant Science 47 (1986) 35-43.

[23] T. Oridate, K. Oosawa, Somatic embryogenesis and plant regeneration from suspension callus culture in melon, Japan J. Breed 36 (1986) 424-428.
[24] X.G. Zhang, P.Y. Liu, Embryogenesis and plant regeneration from cucumber protoplasts, Journal of Southwest Agricultural University 20 (1998) 288-292.

[25] L. Wang, X.Y. Chen, L. Zhang, H.M. Chen, H.Z. Ren, Effect of diffirent factors on induction of embryoids in unfertilized ovaries of cucumber, Acta Agriculturae Boreali-Occidentalis Sinica 17 (2008) 267-270.

[26] M. Usman, Z. Hussain, B. Fatima, Somatic embryogenesis and shoot regeneration induced in cucumber leaves, Pakistan J. Botany 43 (2011) 1283-1393.

[27] X.B. Zheng, G.H. Xia, H. Cui, S.W. Song, H.T. Zhang, Studies on callus induction from Citrullus lanatus seedlings, Journal of Henan Agricultural University 37 (2003) 39-43.

[28] S.W. Song, F. Yan, S.S. Niu, H.X. Miao, Study on somatic embryogenesis and plantlet regeneration from cotyledon of seedless watermelon, Journal of Henan Agricultural University 41 (2007) 269-272, 283.

[29] B. Balen, D. Leljak-Levanic, S. Mihaijević, S. Jelenić, S. Jelaska, Formation of embryogenic callus in hairy roots of pumpkin (Cucurbita pepo L.), In Vitro Cellular \& Developmental Biology-Plant 40 (2004) 182-187.

[30] B. Xie, X.F. Wang, Z.C. Fan, Analysis of the main factors effecting on plantlet regenerating from embryoidvia in vitro gynogenesis in summer squash (Cucurbita pepo L.), Acta Agriculturae Boreali-Occidentalis Sinica 15 (2006) 182-186.

[31] S.N. Kwack, K. Fujieda, Somatic embryogenesis in cultured unfertilized ovules of Cucurbita moschata, J. Jpn. Soc. Hort. Sci. 57 (1988) 34-42.

[32] I. Debeaujon, M. Branchard, Somatic embryogenesis in Cucurbitaceae, Plant Cell, Tissue and Organ Culture 34 (1993) 91-100.

[33] K.R. Cui, K.M. Chen, X.Z. Wang, Y.F. Wang, Current research on plant somatic embryogenesis, Chinese Bulletin of Botany 10 (1993) 14-20.

[34] G. Vengadesan, N. Selvaraj, A.R. Prem, V. Gaba, A. Ganapathi, Ontogeny of somatic embryos in cucumber (Cucumis sativus L.), In Vitro Cellular \& Developmental Biology-Plant 41 (2005) 789-793.

[35] Y.T. Zeng, C.Z. Zhao, L. Lu, Establishment of plant regeneration system through somatic embryogenesis of cotyledons of Cucumis melo 'GT-1', Journal of Gansu Agricultural University 42 (2007) 39-42.

[36] S. Jelaska, Embryogenesis and organogenesis in pumpkin explants, Physiol Plant 31 (1974) 257-261.

[37] Y.W. Yuan, Study on the inductivity of explants of Cucumis Melo, Shihezi University, Shihezi, China, 2007.

[38] T. Oridate, H. Yasawa, Effect of carbohydrates on somatic embryogenesis and embryo development in muskmelon, in: VIIth IAPTC Congress, Amsterdam, 
Holland, 1990, p. 262.

[39] F.X. Xu, S.R. Jia, Somatic embryogenesis from cotyledons of melon and its cytological observations, Journal of Agricultural Biotechnology 2 (1994) 70-77.

[40] J.A.R. Ladyman, B. Girard, Cucumber somatic embryo development on various gelling agents and carbonhydrate source, HortSci 27 (1992) 164-165.

[41] A.F. Yang, Y.M. Zhu, A.J. Hou, Several factors affecting somatic embryos derived from cotyledons of cucumber (Cucumis sativus), Plant Physiology Communications 39 (2003) 206-208.

[42] H. Lou, S. Kako, Role of high sugar concentration in inducing somatic embryogenesis from cucumber cotyledons, SciHortic 64 (1995) 11-20.

[43] P.P. Chee, D.M. Tricoli, Somatic embryogenesis and plant regeneration from cell suspension cultures of Cucumis sativus L., Plant Cell Rep. 7 (1988) 274-277.

[44] P.J. Zhao, H.Y. Sun, M. Peng, Research on plant somatic embryogenesis seedling culture, Modern Agricultural Sciences 16 (2009) 31-32, 58.

[45] S. Mihaljević, S. Radić, N. Bauer, R. Garić, B. Mihaljević, G. Horvat, et al., Ammonium-related metabolic changes affect somatic embryogenesis in pumpkin (Cucurbita pepo L.), Journal of Plant Physiology 168 (2011) 1943-1951.

[46] C.H. Xie, J. Liu, Plant Cell Engineering, Higher Education Press, Beijing, China, 2004.

[47] V. Vasil, I.K. Vasil, Induction and maintenance of embryogenic callus cultures of Gramineae, in: Cell Culture and Somatic Cell Genetics of Plants, 1984, pp. 363.

[48] C. Fischer-Iglesias, B. Sundberg, G. Neuhaus, A.M. Jones, Auxin distribution and transport during embryonic pattern formation in wheat, Plant J. 26 (2001) 115-129.

[49] D.L. Feng, X.S. Meng, Y.H. Wang, X. Liu, M. Li, J. Zhao, et al., Application of exogenous plant growth regulator in plant somatic embryogenesis, Journal of Nuclear Agricultural Sciences 21 (2007) 256-260.

[50] E.F. George, P.D. Sherrington, Plant Propagation by Tissue Culture, Eastern Press, Berks, 1984, p. 352.

[51] D. Dudits, I.A. Bogre, J. Gyorgyey, Molecular and cellular approaches to the analysis of plant embryo development from somatic embryogenesis, J. Cell Sci. 9 (1991) 475.

[52] T. Fujimura, A. Komamine, Synchronization of somatic embryogenesis in a carrot suspension culture, Plant Physiol 64 (1979) 162-164.

[53] V. Raghavan, Role of 2,4-dichlorophenoxyacetic acid (2,4-D) in somatic embryogenesis on cultured zygotic embryos of Arabidopsis: Cell expansion, cell cycling, and morphogenesis during continuous exposure of embryos to 2,4-D, Am. J. Bot. 91 (2004) 1743-1756.

[54] B. Juretić, S. Jelaska, Plant development in long-term embryogenic callus lines of Cucurbita pepo, Plant Cell Rpt 9 (1991) 623-626.

[55] S. Jelaska, Growth and embryoid formation in Cucurbita pepo callus culture, in: Applicationde la Culture In Vitro a l'Amelioration des Plantes Potageres. Reunion EUCARPIA Section "Legumes", 1980, pp. 172-178.

[56] S. Jelaska, V. Magnus, M. Seretin, G. Laćan, Induction of embryogenic callus in Cucurbita pepo hypocotyl explants by indole-3-ethanol and its sugar conjugates, Physiol Plant 64 (1985) 237-242.

[57] M. Noël, D. Comeau, P. Lénée, Embryogenèse somatique de la courgette (Cucurbita pepo L.) à partir de cotyledons, in: Comptes-rendus du ler forum jeunes chercheurs de l'IAPTC-'Du gène à l'entreprise'-Amiens, 1992, pp. 14-18.

[58] S.S. Niu, Studies on Somatic Embryo Induction and Influencing Factors of Citrullus lanatus, Henan Agricultural University, Zhengzhou, China, 2006.

[59] A. Urbanek, B. Zechmann, M. Müller, Plant regeneration via somatic embryogenesis in Styrian pumpkin: Cytological and biochemical investigations, Plant Cell, Tissue and Organ Culture 79 (2005) 329-340.

[60] J.Y. Zhou, F.X. Guo, Actions of cytokinins and cytokinin-like substances in somatic embryogenesis of plant, Plant Physiology Communications 32 (1996) 247-253.

[61] X.M. Wei, M.L. Gao, B. Li, The study on embryo callus induced of melon, Journal of Science of Teachers' College and University 32 (2012) 60-62.

[62] K. Chengalrayan, V.B. Mhaske, S. Hazra, High-frequency conversion of abnormal peanut somatic embryos, Plant Cell Rep. 16 (1997) 783-786.

[63] Y.F. Chen, C.R. Zhang, X. Huang, X.L. Huang, Effect of TDZ on somatic embryogenesis of plant, Plant Physiology Communications 42 (2006) 127-133.

[64] S. Kintzios, E. Sereti, P. Bluchos, J. Drossopoulos, C. Kitsaki, A. Liopa-Tsakalidis, Growth regulator pretreatment improves somatic embryogenesis from leaves of squash (Cucurbita pepo L.) and melon (Cucumis melo L.), Plant Cell Reports 21 (2002) 1-8.

[65] M.E. Compton, D.J. Gray, Somatic embryogenesis and plant regeneration from immature cotyledons of watermelon, Plant Cell Rep. 12 (1993) 61-65.

[66] X.L. Huang, X.J. Li, J.R. Fu, C.L. Lao, Effect of thidiazuron on ethylene production and somatic embryogenesis in callus of Alfalfa (Medicaga sativa L.), Acta Phytophisiologica Sinica 20 (1994) 367-372.

[67] P.P. Chee, Initiation and maturation of somatic embryos of squash (Cucurbito pepo), HortScience 27 (1992) 59-60.

[68] K.R. Cui, R.L. Dai, Molecular Biology of Plant Somatic Embryogenesis, Science Press, Beijing, China, 2000, pp. 
59-62.

[69] L.W. Qi, Y.F. Han, L. Li, E. Dietrich, S.Y. Han, The somatic embryogenesis and establishment of transformation experiment system in Larix principis-rupprechtii, Acta Biologiae Experimentalis Sinica 33 (2000) 357-365.

[70] Y. Wang, C.Z. Liu, X.L. Chen, Somatic embryogenesis in conifers by ABA, Plant Physiology Communications 38 (2002) 273-278.

[71] H. Kamada, H. Harada, Changes in the endogenous level and effects of abscisic acid during somatic embryogenesis of Daucus carota L., Plant Cell Physiol 22 (1981) 1423-1429.

[72] K. Rajasekaran, M.B. Hein, I.K. Vasil, Endogenous abscisic acid and indole-3-acetic acid and somatic embryogenesis in cultured leaf explants of pennisetum purpureum Schum. Effects in vivo and in vitro of glyphosate, Fluridone, and Paclobutrazol, Plant Physiol 84 (1987) 47-51.

[73] K. Takeno, M. Koshioka, R.P. Pharis, K. Rajasekaran, M.G. Mullins, Endogenous gibberellin-like substances in somatic embryos of grape (Vitis vinifera $\times$ Vitis rupestris) in relation to embryogenesis and the chilling requirement for subsequent development of mature embryos, Plant Physiol 73 (1983) 803-808.

[74] S.S. Niu, S.W. Song, F. Yan, H.X. Miao, Somatic embryogenesis and plantlet regeneration in Citrullus lanatus cv. Zhengkang No. 4, Journal of Fruit Science 23 (2006) 406-410.

[75] H.R. Tang, Y.Q. Wang, Z.L. Ren, Somatic embryogenesis in fruit crops, Journal of Sichuan Agricultural University 17 (1999) 69-79.

[76] Y.G. Yang, Y.L. Gui, Z.C. Guo, Studies on somatic embryogenesis and artificial seed of gymnosperms, Seed 77 (1995) 25-30.

[77] S. Fei, P.E. Read, T.P. Riordan, Improvement of embryogenic callus induction and shoot regeneration of buffalo grass by $\mathrm{AgNO}_{3}$, Plant Cell Tissue Organ Culture
60 (2000) 197-203.

[78] S.R.L. Fuentes, M.B.P. Calheiros, J. Manetti-Filho, L.G.E. Vieira, The effects of silver nitrate and different carbohydrate sources on somatic embryogenesis in Coffea canephora, Plant Cell Tissue Organ Culture 60 (2000) 5-13.

[79] P. Giridhar, E.P. Indu, K. Vinod, A. Chandrashekar, G.A. Ravishankar, Direct somatic embryogenesis from Coffea arabica L. and Coffea canephora P. ex Fr. under the influence of ethylene action inhibitor-silver nitrate, Acta Physiologiae Plantarum 26 (2004) 299-305.

[80] Z.Q. Cheng, F. Wang, L.R. Song, S.Y. Pu, X.Q. Huang, Research on increasing the induction ratio of callus from somatic cells in wheat, Southwest China Journal of Agricultural Sciences 12 (1999) 4-8.

[81] S.C. Weatherwax, S.A. Williams, S. Tingay, E.M. Tobin, The phytochrome response of the Lemna gibba NPR1 gene is mediated primarily through changes in abscisic acid levels, Plant Physiol 116 (1998) 1299-1305.

[82] C. Robacker, Somatic embryogenesis and plant regeneration from muscadine grape leaf explants, HortScience 28 (1993) 53-55.

[83] H.T. Zhang, Y.C. Zhai, Z.J. Zhou, F.H. Huang, J.A. Harley, Induction of embryogenic callus and formation of somatic embryo in loblolly pine, Forestry Science and Technology of Guangdong Province 4 (1994) 33-35.

[84] H.Y. Han, L.G. Li, Y.C. Jia, Q.M. Zhang, Studies of somatic embryo via cotyledon induction in Cucumis melon L. 'Hetao', Acta Horticulturae Sinica 32 (2005) 1108-1110.

[85] D.Z. Skinner, A.D. Budde, M.L. Farman, J.R. Smith, H. Leung, S.A. Leong, Genome organization of Magnaporthe grisea: Genetic map, electrophoretic karyotype, and occurrence of repeated DNAs, Theoretical and Applied Genetics 87 (1993) 545-557.

[86] L. Zhang, Establishment of Suspension Culture Line on Momordica charantia L. Cells, Xi Hua University, Chengdu, China, 2007. 